\title{
Thermal stability analysis of functionally graded plates using simple refined plate theory
}

\section{Mokhtar Bouazza ${ }^{1,3 *}$, Abderrahmane Boucheta ${ }^{1}$, Tawfiq Becheri ${ }^{1}$ and Noureddine Benseddiq ${ }^{2}$}

${ }^{1}$ Department of Civil Engineering, University of Bechar, Bechar 08000, Algeria.

${ }^{2}$ Mechanics Laboratory of Lille, CNRS UMR 8107, Ecole Polytech'Lille, University of Lille1, 59655 Villeneuve d'Ascq, France.

${ }^{3}$ Laboratory of Materials and Hydrology (LMH), University of Sidi Bel Abbes, Sidi Bel Abbes 2200, Algeria.

*Email: bouazza_mokhtar@yahoo.fr

Phone: +662462737

\begin{abstract}
The present paper investigates the thermal stability analysis of functionally graded material plates subjected to three types of thermal loadings, namely; uniform temperature rise, linear temperature rise and non-linear temperature rise through the thickness, using a novel simple refined theory. The theory, which has strong similarity with classical plate theory in many aspects, accounts for a quadratic variation of the transverse shear strains across the thickness and satisfies the zero traction boundary conditions on the top and bottom surfaces of the plate without using shear correction factors. Material properties are varied continuously in the thickness direction according to a simple power law distribution. A buckling analysis of a functionally graded plate under there types of thermal loads is carried out and results in closed-form solutions thermal stability analysis of functionally graded plates using simple refined plate theory. The influence of various factors such as gradient index, temperature loads, thickness and aspect ratios are carefully studied. The results are verified with the known data in the literature. This theory is seen to behave well, and the results of the sample problem show good agreement with the literature values as seen from the validation checks.
\end{abstract}

Keywords: Thermal stability; functionally graded plate; simple refined plate theory; thermal loading.

\section{INTRODUCTION}

The multilayered materials are used in many structures. In conventional laminated composite structures, the homogeneous elastic laminate is bonded together to obtain enhanced mechanical and thermal properties [1-3]. The main inconvenience of such an assembly is to create stress concentrations along the interfaces, more specifically when high temperatures are involved. This can lead to delaminations, matrix cracks, and other damage mechanisms which result from the abrupt change of the mechanical properties at the interface between the layer $[3,4]$. One way to overcome this problem is to use functionally graded materials within which material properties vary continuously. The concept of functionally graded material (FGM) was proposed in 1984 by the material scientists in the Sendai area of Japan [1]. The FGM is a composite material whose 
composition varies according to the required performance. It can be produced with a continuously graded variation of the volume fractions of the constituents. That leads to a continuity of the material properties of FGM: this is the main difference between such material and a usual composite material. The FGM is suitable for various applications, such as thermal coatings of a barrier for ceramic engines, gas turbines, nuclear fusions, thin optical layers, biomaterial electronics, etc. [3-14]. Many investigations have been carried out on the subject of mechanical and thermal buckling of structures [3-51]. Developments of new materials such as functionally graded materials (FGMs), however, have necessitated more research in this area. It is observed from the literature that studies involving stability (in terms of buckling) characteristics of FGM plates subjected to thermal [3-25, 46, 47, 52], mechanical loading [26-35], or combinations of [20, 36-42] based on deterministic analysis have received greater attention [43-45].

The response of a functionally graded ceramic-metal plate was investigated by Praveen and Reddy [4] using a finite element model that accounts for the transverse shear strains, rotary inertia, and moderately large rotations in the Von Karman sense. Bouazza et al. [15, 31] reported mechanical and thermal buckling of rectangular and square functionally graded plates (FGPs) based on the classical plate theory. Najafizadeh and Eslami studied the thermoelastic stability of circular functionally graded plates [47]. Three-dimensional thermal buckling analysis of functionally graded materials, using finite element method, is reported by Na and Kim [21]. Matsunaga [22] developed a two-dimensional global higher-order deformation theory for thermal buckling of plates made of FGMs. He calculated the critical buckling temperatures of a simply supported FGP subjected to uniformly and linearly distributed temperatures by Zenkour and Sobhy [23, 24]. Bourada et al. [24] studied the critical bucklingtemperature for FGM sandwich plates.Recently, Akbarzadeh et al. [25] performed an analysis of coupled thermo-elasticity of simply supported FG plates based on the Reddy's TSDT. The plate was subjected to the lateral thermal shock of step function type on the lower side and upper side of the plate is having a convection with the ambient. The material properties of the FG plate, except Poisson's ratio, were assumed to be graded in the thickness direction according to a power-law distribution in terms of the volume fractions of the constituents. Nguyen-Xuan et al. [43] analysed the static, free vibration and mechanical/thermal buckling problems of FG plates using the finite element approach in which a node-based strain smoothing is merged into shearlocking-free triangular plate elements. This work is the extension of the earlier works carried out by the same authors [44, 45] on an edge-based smoothed finite element method (ES-FEM) with stabilized discrete shear gap (DSG) technique using triangular meshes (ES-DSG) to enhance the accuracy of the existing finite element methods for analysis of isotropic Reissner/Mindlin plates. A two variable refined plate theory (RPT) using only two unknown functions was developed by Shimpi [53] for isotropic plates. The most interesting feature of this theory is that it does not require shear correction factor, and has strong similarities with the classical plate theory in some aspects such as governing equation, boundary conditions and moment expressions. Recently, this theory was successfully extended to orthotropic plates $[54,55]$, laminated composite plates $[56$, 57], and functionally graded plates [58]

The purpose of this paper is to develop the four variable refined plate theory for thermal buckling analysis of functionally graded plates. The present theory satisfies equilibrium conditions at the top and bottom faces of the plate without using shear correction factors. Governing equations are derived from the principle of minimum total potential energy. Navier solution is used to obtain the closed-form solutions for simply 
supported FGM plate. To illustrate the accuracy of the present theory, the obtained results are compared with finite element method and results of the first-order shear deformation theory.

\section{THEORETICAL ANALYSIS}

\section{Refined plate theory for FG plates}

The displacement field, which accounts for the parabolic variation of transverse shear stress through the thickness, and satisfies the zero traction boundary conditions on the top and bottom faces of the plate using simple four variable refined shear deformation theory, is assumed as follows [17, 53-58]:

$$
\begin{aligned}
& U(x, y, z)=u(x, y)-z \frac{\partial w_{b}}{\partial x}+z\left[\frac{1}{4}-\frac{5}{3}\left(\frac{z}{h}\right)^{2}\right] \frac{\partial w_{s}}{\partial x} \\
& V(x, y, z)=v(x, y)-z \frac{\partial w_{b}}{\partial y}+z\left[\frac{1}{4}-\frac{5}{3}\left(\frac{z}{h}\right)^{2}\right] \frac{\partial w_{s}}{\partial y} \\
& W(x, y, z)=w_{b}(x, y)+w_{s}(x, y)
\end{aligned}
$$

where $x, y, z$ Cartesian coordinates. $u$ and $v$ are the mid-plane displacements of the plate in the $\mathrm{x}$ and $\mathrm{y}$ directions, respectively; $w_{b}$ and $w_{s}$ are the bending and shear components of transverse displacement, respectively; and $h$ is the plate thickness.

It should be noted that unlike the first-order shear deformation theory, this theory does not require shear correction factors. The kinematic relations can be obtained as follow:

$$
\begin{aligned}
& \varepsilon_{x}=\frac{\partial u}{\partial x}-z \frac{\partial^{2} w_{b}}{\partial x^{2}}-f(z) \frac{\partial^{2} w_{s}}{\partial x^{2}} \\
& \varepsilon_{y}=\frac{\partial v}{\partial y}-z \frac{\partial^{2} w_{b}}{\partial y^{2}}-f(z) \frac{\partial^{2} w_{s}}{\partial y^{2}} \\
& \gamma_{x y}=\frac{\partial u}{\partial y}+\frac{\partial v}{\partial x}-2 z \frac{\partial^{2} w_{b}}{\partial x \partial y}-2 f(z) \frac{\partial^{2} w_{s}}{\partial x \partial y} \\
& \gamma_{y z}=g(z) \frac{\partial w_{s}}{\partial y} \\
& \gamma_{x z}=g(z) \frac{\partial w_{s}}{\partial x} \\
& \varepsilon_{z}=0
\end{aligned}
$$

where

$$
\begin{aligned}
& f(z)=-\frac{1}{4} z+\frac{5}{3} z\left(\frac{z}{h}\right)^{2} \\
& g(z)=\frac{5}{4}-5\left(\frac{z}{h}\right)^{2}
\end{aligned}
$$




\section{Constitutive Relations}

Consider a FGM plate made of ceramic and metal, the material properties of FGM such as material properties vary continuously across the thickness according to the following equations, which are the same as the equations proposed by Reddy et al. and Praveen et al. $[3,4,32,33]$ :

$$
\begin{array}{ll}
E(z)=E_{m}+E_{c m}(z / h+1 / 2)^{k} & E_{c m}=E_{c}-E_{m} \\
\alpha(z)=\alpha_{m}+\alpha_{c m}(z / h+1 / 2)^{k} & \alpha_{c m}=\alpha_{c}-\alpha_{m} \\
v(z)=v_{0} &
\end{array}
$$

For simplicity, Poisson's ratio of the plate is assumed to be constant in this study for that the effect of Poisson's ratio on deformation is much less than that of Young's modulus and thermal expansion [19]. The linear constitutive relations of a FGM platef can be written as [3, 11-14].

$$
\left\{\begin{array}{l}
\sigma_{x} \\
\sigma_{y} \\
\sigma_{x y} \\
\sigma_{y z} \\
\sigma_{x z}
\end{array}\right\}=\left[\begin{array}{ccccc}
Q_{11} & Q_{12} & 0 & 0 & 0 \\
Q_{12} & Q_{22} & 0 & 0 & 0 \\
0 & 0 & Q_{66} & 0 & 0 \\
0 & 0 & 0 & Q_{44} & 0 \\
0 & 0 & 0 & 0 & Q_{55}
\end{array}\right]\left(\left\{\begin{array}{l}
\varepsilon_{x} \\
\varepsilon_{y} \\
\gamma_{x y} \\
\gamma_{y z} \\
\gamma_{x z}
\end{array}\right\}-\alpha T\left\{\begin{array}{l}
1 \\
1 \\
0 \\
0 \\
0
\end{array}\right\}\right)
$$

where

$$
Q_{11}=Q_{22}=\frac{E(z)}{1-v^{2}}, Q_{12}=Q_{11}, Q_{44}=Q_{55}=Q_{66}=\frac{E(z)}{2(1+v)}
$$

\section{Governing Equations}

The strain energy of the plate can be written as $[3,11-14,19]$.

$$
U=\frac{1}{2} \int_{V} \sigma_{i j} \varepsilon_{i j} d V=\frac{1}{2} \int_{V}\left(\sigma_{x}\left(\varepsilon_{x}-\alpha T\right)+\sigma_{y}\left(\varepsilon_{y}-\alpha T\right)+\sigma_{x y} \gamma_{x y}+\sigma_{y z} \gamma_{y z}+\sigma_{x z} \gamma_{x z}\right) d V
$$

The principle of virtual work for the present problem may be expressed as follows

$$
\begin{aligned}
& \iint\left[N_{x} \delta \varepsilon_{x}^{0}+N_{y} \delta \varepsilon_{y}^{0}+N_{x y} \delta \gamma_{x y}^{0}+M_{x}^{b} \delta k_{x}^{b}+M_{y}^{b} \delta k_{y}^{b}+M_{x y}^{b} k_{x y}^{b}+M_{x}^{s} k_{x}^{s}\right. \\
& \left.+M_{y}^{s} k_{y}^{s}+M_{x y}^{s} k_{x y}^{s}+Q_{y z} \gamma_{y z}+Q_{x z} \gamma_{x z}\right] d x d y=0
\end{aligned}
$$

where $\left(N_{x}, N_{y}, N_{x y}\right)$ denote the total in-plane force resultants, $\left(M_{x}^{b}, M_{y}^{b}, M_{x y}^{b}\right)$, $\left(M_{x}^{s}, M_{y}^{s}, M_{x y}^{s}\right)$ denote the total moment resultants and $\left(Q_{x z}, Q_{y z}\right)$ are transverse shear stress resultants and they are defined as 


$$
\begin{aligned}
& \left(N_{x}, N_{y}, N_{x y}\right)=\int_{-h / 2}^{h / 2}\left(\sigma_{x}, \sigma_{y}, \sigma_{x y}\right) d z \\
& \left(M_{x}^{b}, M_{y}^{b}, M_{x y}^{b}\right)=\int_{-h / 2}^{h / 2}\left(\sigma_{x}, \sigma_{y}, \sigma_{x y}\right) z d z \\
& \left(M_{x}^{s}, M_{y}^{s}, M_{x y}^{s}\right)=\int_{-h / 2}^{h / 2}\left(\sigma_{x}, \sigma_{y}, \sigma_{x y}\right) f(z) d z \\
& \left(Q_{x z}, Q_{y z}\right)=\int_{-h / 2}^{h / 2}\left(\sigma_{x z}, \sigma_{y z}\right) g(z) d z
\end{aligned}
$$

Substituting Eq. (5) into Eq. (9) and integrating through the thickness of the plate, the stress resultants are given as

$$
\begin{aligned}
& \left\{\begin{array}{l}
\{N\} \\
\left\{M^{b}\right\} \\
\left\{M^{s}\right\}
\end{array}\right\}=\left[\begin{array}{ccc}
{[A]} & {[B]} & {\left[B^{s}\right]} \\
{[B]} & {[D]} & {\left[D^{s}\right]} \\
{\left[B^{s}\right]} & {\left[D^{s}\right]} & {\left[H^{s}\right]}
\end{array}\right]\left\{\begin{array}{l}
\left\{\varepsilon^{0}\right\} \\
\left\{k^{b}\right\} \\
\left\{k^{s}\right\}
\end{array}\right\}-\left\{\begin{array}{l}
\left\{N^{T}\right\} \\
\left\{M^{b T}\right\} \\
\left\{M^{s T}\right\}
\end{array}\right\} \\
& \left\{\begin{array}{l}
Q_{y z} \\
Q_{x z}
\end{array}\right\}=\left[\begin{array}{cc}
A_{44}^{s} & 0 \\
0 & A_{55}^{s}
\end{array}\right]\left\{\begin{array}{l}
\gamma_{y z}^{s} \\
\gamma_{x z}^{s}
\end{array}\right\}
\end{aligned}
$$

where

$$
\begin{aligned}
& \{N\}=\left\{N_{x}, N_{y}, N_{x y}\right\}^{t},\left\{M^{b}\right\}=\left\{M_{x}^{b}, M_{y}^{b}, M_{x y}^{b}\right\}^{t},\left\{M^{s}\right\}=\left\{M_{x}^{s}, M_{y}^{s}, M_{x y}^{s}\right\}^{t} \\
& \left\{N^{T}\right\}=\left\{N_{x}^{T}, N_{y}^{T}, 0\right\}^{t}, \quad\left\{M^{b T}\right\}=\left\{M_{x}^{b T}, M_{y}^{b T}, 0\right\}^{t},\left\{M^{s T}\right\}=\left\{M_{x}^{s T}, M_{y}^{s T}, 0\right\}^{t} \\
& \left\{\varepsilon^{0}\right\}=\left\{\varepsilon_{x}^{0} ; \varepsilon_{y}^{0} ; \gamma_{x y}^{0}\right\}^{t} ;, \quad\left\{k^{b}\right\}=\left\{k_{x}^{b}, k_{y}^{b}, k_{x y}^{b}\right\}^{t},\left\{k^{s}\right\}=\left\{k_{x}^{s}, k_{y}^{s}, k_{x y}^{s}\right\}^{t}
\end{aligned}
$$

and $A_{i j}, B_{i j}$, etc. are the plate stiffness, defined by

$$
\begin{aligned}
& \left(A_{i j}, B_{i j}, D_{i j}, B_{i j}^{s}, D_{i j}^{s}, H_{i j}^{s}\right)=\int_{-h / 2}^{h / 2} Q_{i j}\left(1, z, z^{2}, f(z), z f(z),(f(z))^{2}\right) d z \quad(i, j=1,2,6) \\
& A_{i j}^{s}=\int_{-h / 2}^{h / 2} Q_{i j}(g(z))^{2} d z \quad(i, j=4,5)
\end{aligned}
$$

The stress and moment resultants, $\left\{N^{T}\right\},\left\{M^{b T}\right\},\left\{M^{s T}\right\}$ due to thermal loading are defined by $[23,24]$.

$$
\left\{N^{T}\right\}=\int_{-h / 2}^{h / 2}\{\beta\} T d z,\left\{M^{b T}\right\}=\int_{-h / 2}^{h / 2}\{\beta\} T z d z, \quad\left\{M^{s T}\right\}=\int_{-h / 2}^{h / 2}\{\beta\} T f(z) d z
$$

where

$$
\{\beta\}=\left\{\begin{array}{c}
\left(Q_{11}+Q_{12}\right) \alpha \\
\left(Q_{12}+Q_{22}\right) \alpha \\
0
\end{array}\right\}
$$


The stability equations of the plate may be derived by the adjacent equilibrium criterion. Assume that the equilibrium state of the FGM plate under thermal loads is defined in terms of the displacement components $\left(u_{0}^{0}, v_{0}^{0}, w_{b}^{0}, w_{s}^{0}\right)$. The displacement components of a neighboring stable state differ by $\left(u_{0}^{1}, v_{0}^{1}, w_{b}^{1}, w_{s}^{1}\right)$ with respect to the equilibrium position. Thus, the total displacements of a neighboring state are

$u_{0}=u_{0}^{0}+u_{0}^{1}, v_{0}=v_{0}^{0}+v_{0}^{1}, w_{b}=w_{b}^{0}+w_{b}^{1}, w_{s}=w_{s}^{0}+w_{s}^{1}$

where the superscript 1 refers to the state of stability and the superscript 0 refers to the state of equilibrium conditions.

Substituting Equations (2) and (15) into Equation (8) and integrating by parts and then equating the coefficients of $\delta u_{0}^{1}, \delta v_{0}^{1}, \delta w_{b}^{1}$ and $\delta w_{s}^{1}$ to zero, separately, the governing stability equations are obtained for the shear deformation plate theories as

$$
\begin{aligned}
& \frac{\partial N_{x}^{1}}{\partial x}+\frac{\partial N_{x y}^{1}}{\partial y}=0 \\
& \frac{\partial N_{x y}^{1}}{\partial x}+\frac{\partial N_{y}^{1}}{\partial y}=0 \\
& \frac{\partial^{2} M_{x}^{b 1}}{\partial x^{2}}+2 \frac{\partial^{2} M_{x y}^{b 1}}{\partial x \partial y}+\frac{\partial^{2} M_{y}^{b 1}}{\partial y^{2}}+\bar{N}=0 \\
& \frac{\partial^{2} M_{x}^{s 1}}{\partial x^{2}}+2 \frac{\partial^{2} M_{x y}^{s 1}}{\partial x \partial y}+\frac{\partial^{2} M_{y}^{s 1}}{\partial y^{2}}+\frac{\partial Q_{x z}^{s 1}}{\partial x}+\frac{\partial Q_{y z}^{s 1}}{\partial y}+\bar{N}=0
\end{aligned}
$$

with

$$
\begin{aligned}
& \bar{N}=N_{x}^{0} \frac{\partial^{2}\left(w_{b}^{1}+w_{s}^{1}\right)}{\partial x^{2}}+N_{y}^{0} \frac{\partial^{2}\left(w_{b}^{1}+w_{s}^{1}\right)}{\partial y^{2}} \\
& N_{x}^{0}=N_{y}^{0}=-\frac{\int_{-h / 2}^{h / 2} E(z) \alpha(z) T d z}{1-v}
\end{aligned}
$$

\section{Thermal Buckling Solution}

Following the Navier solution procedure, the following approximate solution is seen to satisfy both the differential equation and the boundary conditions [14, 32, 33, 53-58].

$$
\left\{\begin{array}{l}
u_{0}^{1} \\
v_{0}^{1} \\
w_{b}^{1} \\
w_{s}^{1}
\end{array}\right\}=\sum_{m=1}^{\infty} \sum_{n=1}^{\infty}\left\{\begin{array}{c}
U_{m n}^{1} \cos \lambda x \sin \mu y \\
V_{m n}^{1} \sin \lambda x \cos \mu y \\
W_{b m n}^{1} \sin \lambda x \sin \mu y \\
W_{s m n}^{1} \sin \lambda x \sin \mu y
\end{array}\right\}
$$


where

$U_{m n}^{1}, V_{m n}^{1}, W_{b m n}^{1}, W_{s m n}^{1}$ are arbitrary parameters to be determined and $\lambda=m \pi / a$ and $\mu=n \pi / b$. Substituting Equation (19) into Equation (16), one obtains

$[S]\{\Delta\}=0$

where $\{\Delta\}$ denotes the column and $[S]$ is the symmetric matrix given by

$\left[\begin{array}{llll}s_{11} & s_{12} & s_{13} & s_{14} \\ s_{12} & s_{22} & s_{23} & s_{24} \\ s_{13} & s_{23} & s_{33} & s_{34} \\ s_{14} & s_{24} & s_{34} & s_{44}\end{array}\right]$

in which:

$$
\begin{aligned}
& s_{11}=A_{11} \lambda^{2}+A_{66} \mu^{2}, \quad s_{12}=\lambda \mu\left(A_{12}+A_{66}\right), \quad s_{22}=A_{66} \lambda^{2}+A_{22} \mu^{2}, \\
& s_{13}=-\lambda\left[B_{11} \lambda^{2}+\left(B_{12}+2 B_{66}\right) \mu^{2}\right], \quad s_{14}=-\lambda\left[B_{11}^{s} \lambda^{2}+\left(B_{12}^{s}+2 B_{66}^{s}\right) \mu^{2}\right], \\
& s_{23}=-\mu\left[\left(B_{12}+2 B_{66}\right) \lambda^{2}+B_{22} \mu^{2}\right], \quad s_{24}=-\mu\left[\left(B_{12}^{s}+2 B_{66}^{s}\right) \lambda^{2}+B_{22}^{s} \mu^{2}\right], \\
& s_{33}=D_{11} \lambda^{4}+2\left(D_{12}+2 D_{66}\right) \lambda^{2} \mu^{2}+D_{22} \mu^{4}+N_{x}^{0}\left(\lambda^{2}+\mu^{2}\right) \\
& s_{34}=D_{11}^{s} \lambda^{4}+2\left(D_{12}^{s}+2 D_{66}^{s}\right) \lambda^{2} \mu^{2}+D_{22}^{s} \mu^{4}+N_{x}^{0}\left(\lambda^{2}+\mu^{2}\right) \\
& s_{44}=H_{11}^{s} \lambda^{4}+2\left(H_{12}^{s}+2 H_{66}^{s}\right) \lambda^{2} \mu^{2}+H_{22}^{s} \mu^{4}+A_{55}^{s} \lambda^{2}+A_{44}^{s} \mu^{2}+N_{x}^{0}\left(\lambda^{2}+\mu^{2}\right),
\end{aligned}
$$

By applying the condensation approach to eliminate the in-plane displacements $U_{m n}^{1}$ and $V_{m n}^{1}$, Eq. (20) can be rewritten as

$[\bar{S}]\{\bar{\Delta}\}=0$

Where

$$
\begin{aligned}
& {[\bar{S}]=\left[\begin{array}{ll}
\bar{S}_{33} & \bar{S}_{43} \\
\bar{S}_{43} & \bar{S}_{44}
\end{array}\right]} \\
& {[\bar{\Delta}]=\left\{\begin{array}{l}
W_{b m n} \\
W_{s m n}
\end{array}\right\}}
\end{aligned}
$$

and

$$
\begin{aligned}
& \bar{s}_{33}=s_{33}-s_{13} \frac{b_{1}}{b_{0}}-s_{23} \frac{b_{2}}{b_{0}}+N_{x}^{0}\left(\lambda^{2}+\mu^{2}\right), \bar{s}_{34}=s_{34}-s_{14} \frac{b_{1}}{b_{0}}-s_{24} \frac{b_{2}}{b_{0}}+N_{x}^{0}\left(\lambda^{2}+\mu^{2}\right), \\
& \bar{s}_{43}=s_{34}-s_{13} \frac{b_{3}}{b_{0}}-s_{23} \frac{b_{4}}{b_{0}}+N_{x}^{0}\left(\lambda^{2}+\mu^{2}\right), \bar{s}_{44}=s_{44}-s_{14} \frac{b_{3}}{b_{0}}-s_{24} \frac{b_{4}}{b_{0}}+N_{x}^{0}\left(\lambda^{2}+\mu^{2}\right), \\
& b_{0}=s_{11} s_{22}-s_{12}^{2}, b_{1}=s_{13} s_{22}-s_{12} s_{23}, b_{2}=s_{11} s_{23}-s_{12} s_{13}, b_{3}=s_{14} s_{22}-s_{12} s_{24}, b_{4}=s_{11} s_{24}-s_{12} s_{14}
\end{aligned}
$$


In the following, the solution of the equation $\left|S_{i j}\right|=0$ for different types of thermal loading conditions and by using refined plate theory is presented. The plate is assumed simply supported. The temperature change is varied only through-thethickness.

\section{Buckling of FGM plates under uniform temperature rise}

The initial plate temperature is assumed to be $T_{i}$. The temperature is uniformly raised to a final value $T_{f}$ in which the plate buckles. The temperature change is $\Delta T=T_{f}-T_{i}$. Substituting prebuckling forces from Eqs. (18) into the matrix $\bar{S}$ and setting $|\bar{S}|=0$ to obtain the nonzero solution, the value of $\Delta T$ is found as

$$
\Delta T_{c r}=\frac{(1-v)}{P\left(\lambda^{2}+\mu^{2}\right)} \frac{\left(\bar{s}_{33} \bar{s}_{44}-\bar{s}_{34} \bar{s}_{43}\right)}{\left(\bar{s}_{33}+\bar{s}_{44}-\bar{s}_{34}-\bar{s}_{43}\right)}
$$

where

$$
P=\int_{-h / 2}^{h / 2} E(z) \alpha(z) d z
$$

For the case of CPT, the expression of critical buckling temperature can be simplified by setting the shear component of transverse displacement to zero $\left(w_{s}=0\right)$ as

$$
\Delta T_{c r}=\frac{(1-v) \bar{s}_{33}}{P\left(\lambda^{2}+\mu^{2}\right)}
$$

The critical temperature difference is obtained for the values of $m, n$ that makes the preceding expression a minimum. Apparently, when minimization methods are used, the critical temperature difference is obtained for $\mathrm{m}=\mathrm{n}=1$.

\section{Buckling of FGM plates subjected to Graded Temperature Change Across the Thickness}

We assume that the temperature of the top surface is $T_{m}$ and the temperature varies from $T_{m}$, according to the power law variation through-the-thickness, to the bottom surface temperature $T_{c}$ in which the plate buckles. In this case, the temperature through the thickness is given by $[17,23,24]$

$$
T(z)=\Delta T\left(\frac{z}{h}+\frac{1}{h}\right)^{g}+T_{m}
$$

where $\mathrm{z}$ is the coordinate variable in the thickness direction which measured from the middle plane of the plate. 
The buckling temperature difference $\Delta T=T_{c}-T_{m}$ and $\gamma$ is the temperature exponent $(0<g<\infty)$. Note that the value of $\gamma$ equal to unity represents a linear temperature change across the thickness. While the value of $\gamma$ excluding unity represents a non-linear temperature change through-the-thickness. Similar to the previous loading case, the critical buckling temperature change $\Delta T_{c r}$ can be deduced, for the refined plate theory, as

$\Delta T_{c r}=\frac{\frac{(1-v)}{\left(\lambda^{2}+\mu^{2}\right)} \frac{\left(\bar{s}_{33} \bar{s}_{44}-\bar{s}_{34} \bar{s}_{43}\right)}{\left(\bar{s}_{33}+\bar{s}_{44}-\bar{s}_{34}-\bar{s}_{43}\right)}-P T_{m}}{X}$

where

$$
X=\int_{-h / 2}^{h / 2} E(z) \alpha(z)\left(\frac{z}{h}+\frac{1}{h}\right)^{\gamma} d z
$$

For the case of CPT, the expression of critical buckling temperature can be simplified by setting the shear component of transverse displacement to zero $\left(w_{s}=0\right)$ as

$$
\Delta T_{c r}=\frac{\frac{(1-v) \bar{s}_{33}}{\left(\lambda^{2}+\mu^{2}\right)}-P T_{m}}{X}
$$

\section{RESULTS AND DISCUSSION}

Firstly, based on the derived formulation, a computer program is developed to study the behavior of simply supported functionally graded plates in thermal buckling using refined plate theory. The analysis is performed for pure materials and different values volume fraction functions, for aluminum-alumina functionally graded plates. The properties of constituent materials, including Young's modulus, the coefficient of the thermal expansion and Poisson's ratio coefficient are given in Table 1.

Table 1. Material properties of metal and ceramics [3, 11-15].

\begin{tabular}{llll}
\hline & \multicolumn{3}{c}{ Property } \\
\cline { 2 - 4 } Material & $\mathrm{E}(\mathrm{GPa})$ & $v$ & $\alpha\left(1 /{ }^{\circ} \mathrm{C}\right)$ \\
\hline Aluminum & 70 & 0.3 & $23 \mathrm{e}-6$ \\
Alumina & 380 & 0.3 & $7.4 \mathrm{e}-6$ \\
\hline
\end{tabular}

\section{Isotropic Plates}

In order to prove the validity of the present formulation, results were obtained for isotropic plates and compared with the existing ones in the literature. The critical temperatures of simply supported, isotropic square plates subjected to constant and linearly varying temperature distributions obtained using four variable refined plate theory are verified against the energy method based results of Gowda and Pandalai [59], solution of Kari et al [60] based on finite element method using semiloof element and 
solution of Bouazza et al [12] based on first order shear deformation theory in Table 2. Both results are in excellent agreement.

Table 2. Critical temperature for isotropic square plates subjected to different forms of temperature distribution $\left(a / h=100, \alpha=2 \cdot 10^{-6}, v=0.3\right)$.

\begin{tabular}{lllll}
\hline Temperature distribution & $\begin{array}{l}\text { Gowda and } \\
\text { Pandalai }\end{array}$ & $\begin{array}{l}\text { Kri et al } \\
{[60]}\end{array}$ & $\begin{array}{l}\text { Bouazza et al } \\
{[12]}\end{array}$ & Present \\
\hline Uniform temperature rise & 63.27 & 63.33 & 63.237 & 63.231 \\
Linear temperature rise & 126.54 & 126.00 & 126.474 & 126.462 \\
\hline
\end{tabular}

In addition, the buckling loads for simply supported, isotropic plates under uniform temperature rise are calculated using four variable refined plate theory. Isotropic homogeneous plate obtained by the proposed approach and the available data in the literature $(\mathrm{k}=0)$ or $E_{c}=E_{m}=E$, and compared in Figure 1 with finite element results obtained by Kari et al. [60] and analytical approach using first order shear deformation theory obtained by Bouazza et al. [12]. It can be seen that for most cases the present results agree well with existing results.

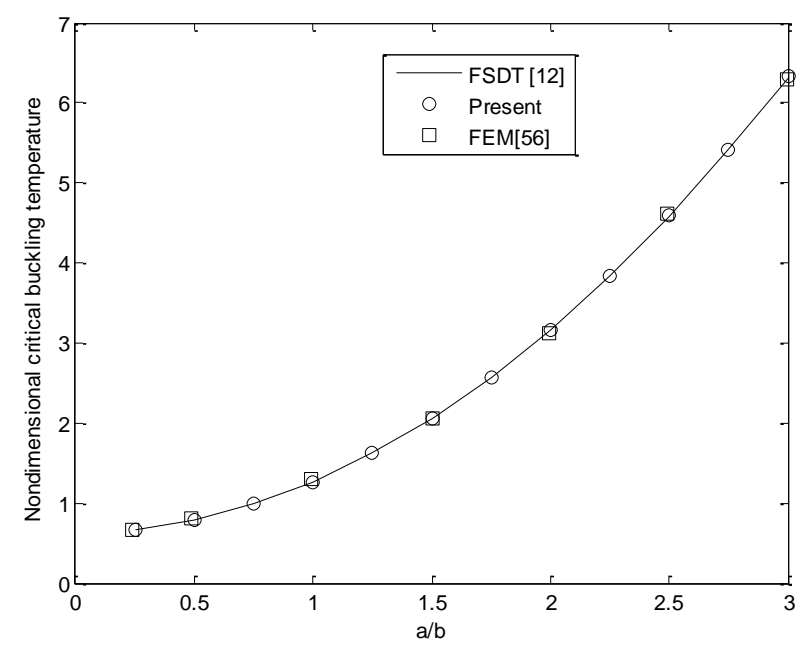

Figure 1 . The critical temperature of simply supported isotropic plates $(\mathrm{a} / \mathrm{h}=100)$.

\section{Functionally Graded Plates}

The buckling loads of ceramic-metal functionally graded plates (FGM), a comparison has been carried out with the results obtained by Javaheri and Eslami [18] based on the HSDT, for all edges simply supported FGM plates and the results obtained by Bodaghi and Saidi [19] based on the higher-order shear deformation plate theory of Reddy, for two opposite edges simply supported FGM plates and the results obtained by Chen [20] et al based on the using the average stress method, including the effect of transverse shear deformation. The critical buckling temperature difference has been listed in Tables 3 , and 4 for a square simply supported plate subjected to different temperature distribution across the thickness and side-thickness ratios. All thermal buckling coefficient presented in Tables 3 and 4 are defined as $T_{c r}=10^{-3} \Delta T_{c r}$. As this table shows, the present results have an excellent agreement with those reported in Ref. [18] ,Ref. [19] and Ref. [20]. 
The next comparison is performed for simply supported plates subjected to linear temperature distribution across the thickness. The plate is made from a mixture of Aluminum $(\mathrm{Al})$ and aluminium $\left(\mathrm{Al}_{2} \mathrm{O}_{3}\right)$. The critical buckling temperature difference of simply supported plate for different values of thickness ratio $b / h$, , and power law index $\mathrm{k}$ are shown in Table 4. It can be seen that, for most cases the present results agree well with existing results reported by Javaheri [18] and Eslami and Bodaghi and Saidi [11] . The results the critical temperature for various values of the volume fraction index $(\mathrm{k})$ and thickness-to-length ratio $\mathrm{a} / \mathrm{h}$ are in excellent agreement with results by Javaheri and Eslami [18], Bodaghi and Saidi [19] and Chen [20] et al. As can be observed the critical temperature decreases both when increasing the volume fraction index $\mathrm{k}$ and when increasing the thickness-to-length ratio $\mathrm{a} / \mathrm{h}$.

Table3. Comparison of the critical buckling temperature difference for a simply supported functionally graded plate subjected to uniform temperature load $(\mathrm{a} / \mathrm{b}=1)$.

\begin{tabular}{llllllll}
\hline $\mathrm{k}$ & Theories & $\mathrm{b} / \mathrm{h}=10$ & $\mathrm{~b} / \mathrm{h}=20$ & $\mathrm{~b} / \mathrm{h}=40$ & $\mathrm{~b} / \mathrm{h}=60$ & $\mathrm{~b} / \mathrm{h}=80$ & $\mathrm{~b} / \mathrm{h}=100$ \\
\hline 0 & Ref.[19] & 1,61748 & 0,42152 & 0,10649 & 0,04742 & 0,02669 & 0,01709 \\
& Ref.[20] & 1,61748 & 0,42152 & 0,10649 & 0,04742 & 0,02669 & 0,01709 \\
& Ref.[21] & 1,5939 & 0,41974 & 0,10637 & 0,0474 & 0,02668 & 0,01708 \\
& Present & 1,61868 & 0,42153 & 0,10649 & 0,04742 & 0,02669 & 0,01709 \\
\hline 1 & Ref.[19] & 0,75789 & 0,19626 & 0,0495 & 0,02204 & 0,0124 & 0,00794 \\
& Ref.[20] & 0,75789 & 0,19626 & 0,0495 & 0,02204 & 0,0124 & 0,00794 \\
& Ref.[21] & 0,74608 & 0,19539 & 0,04944 & 0,02202 & 0,0124 & 0,00794 \\
& Present & 0,7584 & 0,19627 & 0,0495 & 0,02204 & 0,0124 & 0,00794 \\
\hline 5 & Ref.[19] & 0,67893 & 0,17853 & 0,04521 & 0,02014 & 0,01134 & 0,00726 \\
& Ref.[20] & 0,67893 & 0,17853 & 0,04521 & 0,02014 & 0,01134 & 0,00726 \\
& Ref.[21] & 0,67251 & 0,17799 & 0,04517 & 0,02013 & 0,01134 & 0,00726 \\
& Present & 0,67931 & 0,17854 & 0,04521 & 0,02014 & 0,01134 & 0,00726 \\
\hline 10 & Ref.[19] & 0,69252 & 0,18314 & 0,04646 & 0,0207 & 0,01166 & 0,00746 \\
& Ref.[20] & 0,69252 & 0,18314 & 0,04645 & 0,0207 & 0,01166 & 0,00746 \\
& Ref.[21] & 0,68704 & 0,18265 & 0,04641 & 0,02069 & 0,01165 & 0,00746 \\
& Present & 0,69269 & 0,18315 & 0,04646 & 0,0207 & 0,01166 & 0,00746 \\
\hline
\end{tabular}

Table4. Comparison of the critical buckling temperature difference for a simply supported functionally graded plate subjected to linear temperature load $(\mathrm{a} / \mathrm{b}=1)$.

\begin{tabular}{llllllll}
\hline $\mathrm{k}$ & Theories & $\mathrm{b} / \mathrm{h}=10$ & $\mathrm{~b} / \mathrm{h}=20$ & $\mathrm{~b} / \mathrm{h}=40$ & $\mathrm{~b} / \mathrm{h}=60$ & $\mathrm{~b} / \mathrm{h}=80$ & $\mathrm{~b} / \mathrm{h}=100$ \\
0 & Ref[18] & 3,22497 & 0,83303 & 0,20298 & 0,08485 & 0,04339 & 0,02418 \\
& Ref.[19] & 3,22497 & 0,83303 & 0,20298 & 0,08485 & 0,04339 & 0,02418 \\
& Present & 3,22736 & 0,83307 & 0,20299 & 0,08485 & 0,04339 & 0,02418 \\
\hline 1 & Ref.[18] & 1,41202 & 0,3587 & 0,08346 & 0,03195 & 0,03195 & 0,00551 \\
& Ref.[19] & 1,41202 & 0,3587 & 0,08346 & 0,03195 & 0,03195 & 0,00551 \\
& Present & 1,41297 & 0,35871 & 0,08346 & 0,03195 & 0,03195 & 0,00551 \\
\hline 5 & Ref.[18] & 1,16002 & 0,29869 & 0,06922 & 0,02607 & 0,01091 & 0,00389 \\
& Ref.[19] & 1,16002 & 0,29869 & 0,06922 & 0,02607 & 0,01091 & 0,00389 \\
& Present & 1,16069 & 0,29871 & 0,06922 & 0,02607 & 0,01091 & 0,00389 \\
\hline 10 & Ref.[18] & 1,21833 & 0,31568 & 0,07346 & 0,02783 & 0,0118 & 0,00436 \\
& Ref.[19] & 1,21833 & 0,31568 & 0,07346 & 0,02783 & 0,0118 & 0,00436 \\
& Present & 1,21864 & 0,31568 & 0,07346 & 0,02783 & 0,0118 & 0,00437 \\
\hline
\end{tabular}




\section{Buckling Analysis of FGM plates}

The non-dimensional critical buckling temperature or temperature differences $T_{c r}=\Delta T_{c r} \alpha_{c} 10^{3}$ concerning the material gradient indexes of the plate are calculated for functionally graded squares plates with a different relative thickness of the plate under uniform temperature rise, linear and nonlinear temperature distribution across the thickness using the four variable refined plate theory and are plotted in Figure 2. It is clear that the non-dimensional critical temperature under non-linear temperature rise is higher than that under linear temperature rise. The non-dimensional critical temperature under non-linear temperature rise is higher than that under uniform temperature rise, whatever the gradient index $\mathrm{k}$ is. In all type of temperature cases (uniform, linear, nonlinear), the critical temperature change decreases, when the volume fraction index $\mathrm{k}$ $\mathrm{a} / \mathrm{h}$ is increased. On the other hand, the critical temperature change increases, when the relative thickness of the plate $\mathrm{a} / \mathrm{h}$ is decreased. It should be noted that the present theory involves only four independent variables as against five in the case of HSDT [18, 19] and FSDT [20]. Also, the present theory does not require shear correction factors as in the case of FSDT. It can be concluded that the present theory is not only accurate but also efficient in predicting critical buckling load of FGM plates.

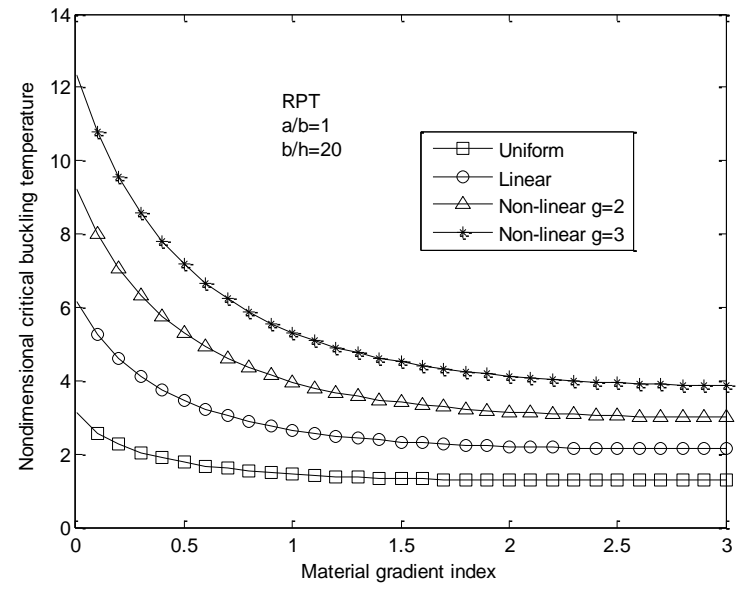

(a) $b / h=20$

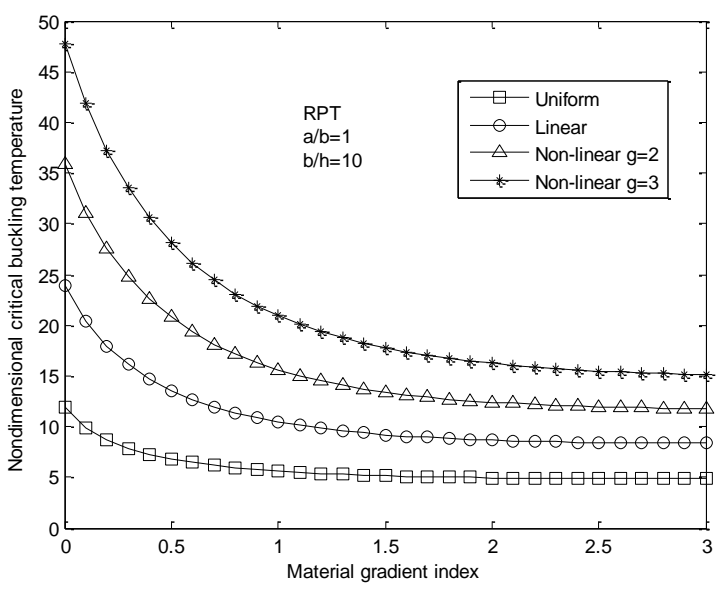

(b) $b / h=10$

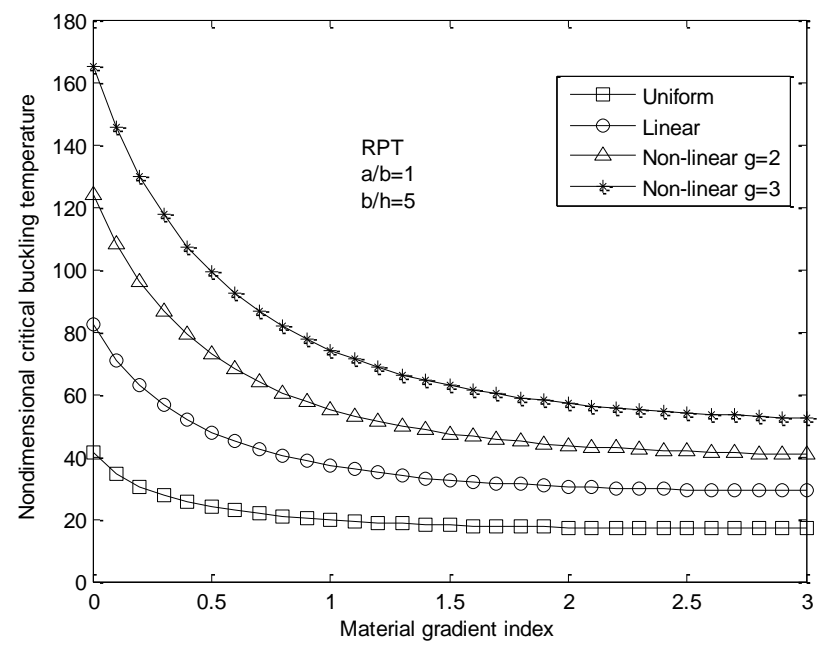

(c) $b / h=5$

Figure 2. Non-dimensional critical buckling temperature of FGM plate under uniform linear and nonlinear temperature rise versus gradient index of the plate. 


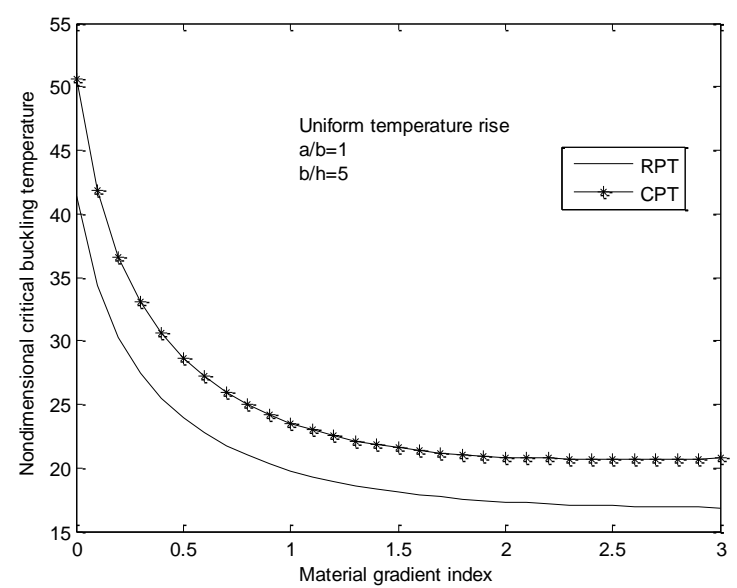

(a) Uniform temperature rise

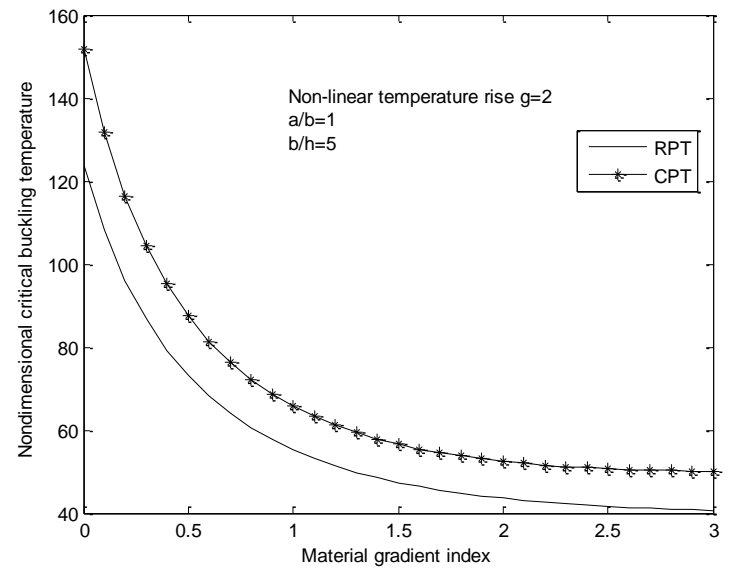

(c) Non-linear temperature raise $(\mathrm{g}=2)$

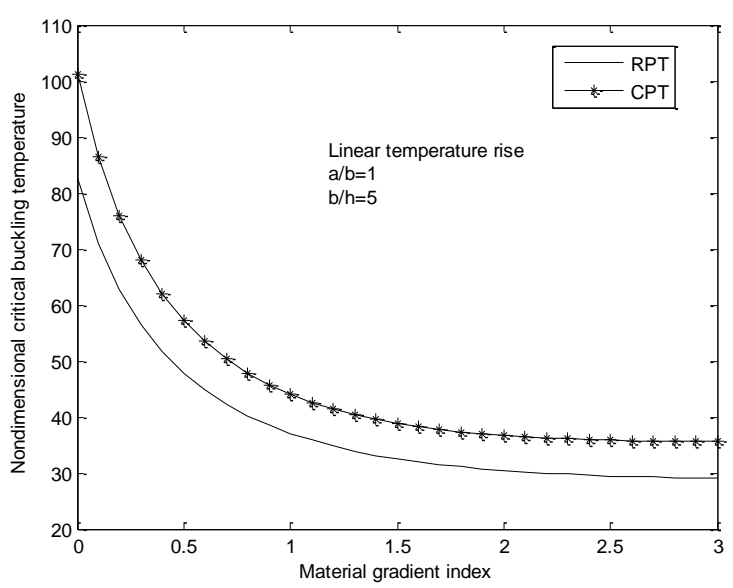

(b) Linear temperature raise

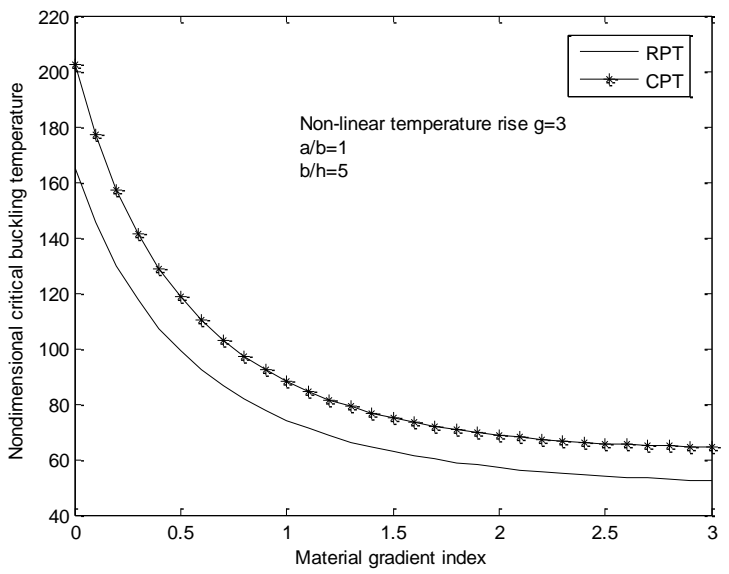

(d) Non-linear temperature raise $(g=3)$

Figure 3. Non-dimensional critical buckling temperature of FGM plate under uniform, linear, non-linear ( $\mathrm{g}=2$ and 3 ) temperature rise versus gradient index of the plate.

Figure 3 shows the comparison the four variable refined plate theory with the classic plate theory variation for non-dimensional critical temperature difference vs material gradient index $k$. The plate aspect ratio is set as $\mathrm{a} / \mathrm{b}=1$ and the relative thickness of the plate is set as $b / h=5$. The plates subjected under uniform temperature rise, linear and nonlinear temperature distribution across the thickness respectively. It is observed that with increasing the material gradient index $\mathrm{k}$ from 0 to 3 , the nondimensional critical buckling temperature difference also decreases steadily. The same remark is observed in. [6, 11-14, 28-35] The values of the critical temperature differences calculated by using the four variable refined plate theory are lower than those calculated by using the classical plate theory. In conclusion, the transverse shear deformation has some effect on the buckling temperature difference. It is also observed that the CPT overestimates the critical buckling load of FG plates.

\section{CONCLUSIONS}

The thermal buckling analysis of functionally graded plates is carried out by using four variable refined plate theory. Material properties varied continuously in the thickness direction according to a simple power law distribution in terms of the volume fraction of 
a ceramic and metal. Then the buckling analysis of functionally graded plates under these types of thermal loadings is presented. Closed form solutions for the critical buckling temperature differences of plates are presented. Based on the numerical results, the following conclusions are reached:

i) Present results agree well with the previously published results in the literature.

ii) The critical temperature decreases as volume fraction index are increased. In addition, the critical temperature increases when the geometric parameter $\mathrm{b} / \mathrm{h}$ is decreased.

iii) The critical temperature under nonlinear temperature rise is higher than that under linear temperature rise and uniform temperature rise.

iv) Transverse shear deformation has considerable effect on the critical buckling temperature difference of functionally graded plate.

v) It is believed that the tabulated results will be a reference with which other researchers can compare their results.

\section{ACKNOWLEDGEMENTS}

This research was supported by the University of Bechar, Algeria; Laboratory of Materials and Hydrology (LMH), University of Sidi Bel Abbes in Algeria and Mechanics Laboratory of Lille, CNRS, Ecole Polytech'Lille, France.

\section{REFERENCES}

[1] Koizumi M. FGM activities in Japan. Composites Part B: Engineering. 1997;28:1-4.

[2] Fuchiyama T, Noda N. Analysis of thermal stress in a plate of functionally gradient material. JSAE review. 1995;16:263-8.

[3] Reddy J, Chin C. Thermomechanical analysis of functionally graded cylinders and plates. Journal of thermal Stresses. 1998;21:593-626.

[4] Praveen G, Reddy J. Nonlinear transient thermoelastic analysis of functionally graded ceramic-metal plates. International Journal of Solids and Structures. 1998;35:4457-76.

[5] Shen H-S. Postbuckling analysis of axially-loaded functionally graded cylindrical shells in thermal environments. Compos Sci Technol. 2002;62:97787.

[6] Lanhe W. Thermal buckling of a simply supported moderately thick rectangular FGM plate. Composite Structures. 2004;64:211-8.

[7] Samsam Shariat B, Eslami M. Effect of initial imperfections on thermal buckling of functionally graded plates. Journal of thermal stresses. 2005;28:1183-98.

[8] Vel SS, Batra R. Exact solution for thermoelastic deformations of functionally graded thick rectangular plates. AIAA journal. 2002;40:1421-33.

[9] Zimmerman RW, Lutz MP. Thermal stresses and thermal expansion in a uniformly heated functionally graded cylinder. Journal of Thermal Stresses. 1999;22:177-88.

[10] Ganapathi M, Prakash T. Thermal buckling of simply supported functionally graded skew plates. Composite Structures. 2006;74:247-50. 
[11] Saidi A, Baferani AH. Thermal buckling analysis of moderately thick functionally graded annular sector plates. Composite Structures. 2010;92:174452.

[12] Bouazza M, Tounsi A, Adda-Bedia EA, Megueni A. Thermoelastic stability analysis of functionally graded plates: An analytical approach. Computational Materials Science. 2010;49:865-70.

[13] Bouazza M, Tounsi A, Adda-Bedia EA, Megueni A. Stability analysis of functionally graded plates subject to thermal loads. Shell-like Structures: Springer; 2011. p. 669-80.

[14] Bouazza M, Tounsi A, Adda-Bedia E, Megueni A. Thermal buckling behavior of functionally graded material. Journal of Materials Science and Technology. 2010;18:155-70.

[15] Bouazza M, Tounsi A, Adda-Bedia EA, Megueni A. Thermal buckling of simply supported FGM square plates. Applied Mechanics and Materials: Trans Tech Publ; 2011. p. 25-32.

[16] Atmane H, Bedia E, Bouazza M, Tounsi A, Fekrar A. On the thermal buckling of simply supported rectangular plates made of a sigmoid functionally graded Al/A12. Mechanics of Solids. 2016;51:177-87.

[17] Bouazza M, Becheri T, Boucheta A, Benseddiq N. Thermal buckling analysis of nanoplates based on nonlocal elasticity theory with four-unknown shear deformation theory resting on Winkler-Pasternak elastic foundation. International Journal for Computational Methods in Engineering Science and Mechanics. 2016;17:362-73.

[18] Javaheri R, Eslami M. Thermal buckling of functionally graded plates based on higher order theory. Journal of thermal stresses. 2002;25:603-25.

[19] Bodaghi M, Saidi A. Thermoelastic buckling behavior of thick functionally graded rectangular plates. Archive of Applied Mechanics. 2011;81:1555-72.

[20] Chen CS, Lin CY, Chien RD. Thermally induced buckling of functionally graded hybrid composite plates. International Journal of Mechanical Sciences. 2011;53:51-8.

[21] Na K-S, Kim JH. Three-dimensional thermal buckling analysis of functionally graded materials. Composites Part B: Engineering. 2004;35:429-37.

[22] Matsunaga $\mathrm{H}$. Thermal buckling of functionally graded plates according to a $2 \mathrm{D}$ higher-order deformation theory. Composite Structures. 2009;90:76-86.

[23] Zenkour A, Sobhy M. Thermal buckling of various types of FGM sandwich plates. Composite Structures. 2010;93:93-102.

[24] Bourada M, Tounsi A, Houari MSA, Bedia EAA. A new four-variable refined plate theory for thermal buckling analysis of functionally graded sandwich plates. Journal of Sandwich Structures \& Materials. 2012;14:5-33.

[25] Akbarzadeh A, Abbasi M, Eslami M. Coupled thermoelasticity of functionally graded plates based on the third-order shear deformation theory. Thin-Walled Structures. 2012;53:141-55.

[26] Yanga J, Shen HS. Non-linear analysis of functionally graded plates under transverse and in-plane loads. International Journal of Non-Linear Mechanics. 2003;38:467-82.

[27] Feldman E, Aboudi J. Buckling analysis of functionally graded plates subjected to uniaxial loading. Composite Structures. 1997;38:29-36.

[28] Javaheri R, Eslami M. Buckling of Functionally Graded Plates under In-plane Compressive Loading. ZAMM-Journal of Applied Mathematics and 
Mechanics/Zeitschrift für Angewandte Mathematik und Mechanik. 2002;82:277-83.

[29] Thai HT, Choi DH. An efficient and simple refined theory for buckling analysis of functionally graded plates. Applied Mathematical Modelling. 2012;36:100822.

[30] Wu TL, Shukla K, Huang JH. Post-buckling analysis of functionally graded rectangular plates. Composite structures. 2007;81:1-10.

[31] Bouazza M, Ouinas D, Yazid A, Hamouine A. Buckling of thin plates under uniaxial and biaxial compression. Journal of Materials Science and Engineering A. 2012;2:487.

[32] Bouazza M, Amara K, Benseddiq N. Mechanical Buckling Analysis of Functionally Graded Plates Using a New Refined Theory. Jordan Journal of Civil Engineering. 2017;11.

[33] Boucheta A, Bouazza M, Becheri T, Benseddiq N. Hyperbolic four variable refined shear deformation theory for mechanical buckling analysis of functionally graded plates. UPB Sci Bull Ser D. 2016;78:65-78.

[34] Becheri T, Amara K, Bouazza M, Benseddiq N. Buckling of symmetrically laminated plates using nth-order shear deformation theory with curvature effects. Steel and Composite Structures. 2016;21:1347-68.

[35] Najafizadeh M, Eslami M. Buckling analysis of circular plates of functionally graded materials based on first order theory. 2002.

[36] Zhao X, Lee Y, Liew KM. Mechanical and thermal buckling analysis of functionally graded plates. Composite Structures. 2009;90:161-71.

[37] Shen H-S. Postbuckling of FGM plates with piezoelectric actuators under thermo-electro-mechanical loadings. International Journal of Solids and Structures. 2005;42:6101-21.

[38] Na K-S, Kim J-H. Three-dimensional thermomechanical buckling analysis for functionally graded composite plates. Composite structures. 2006;73:413-22.

[39] Woo J, Meguid S, Stranart J, Liew K. Thermomechanical postbuckling analysis of moderately thick functionally graded plates and shallow shells. International Journal of Mechanical Sciences. 2005;47:1147-71.

[40] Ma L, Wang T. Nonlinear bending and post-buckling of a functionally graded circular plate under mechanical and thermal loadings. International Journal of Solids and Structures. 2003;40:3311-30.

[41] Lee Y, Zhao X, Reddy J. Postbuckling analysis of functionally graded plates subject to compressive and thermal loads. Computer Methods in Applied Mechanics and Engineering. 2010;199:1645-53.

[42] Duc ND, Van Tung H. Mechanical and thermal postbuckling of higher order shear deformable functionally graded plates on elastic foundations. Composite Structures. 2011;93:2874-81.

[43] Nguyen-Xuan H, Tran LV, Thai CH, Nguyen-Thoi T. Analysis of functionally graded plates by an efficient finite element method with node-based strain smoothing. Thin-Walled Structures. 2012;54:1-18.

[44] Nguyen T-K, Sab K, Bonnet G. First-order shear deformation plate models for functionally graded materials. Composite Structures. 2008;83:25-36.

[45] Nguyen-Xuan H, Tran LV, Nguyen-Thoi T, Vu-Do H. Analysis of functionally graded plates using an edge-based smoothed finite element method. Composite Structures. 2011;93:3019-39. 
[46] Bouazza M, Lairedj A, Benseddiq N, Khalki S. A refined hyperbolic shear deformation theory for thermal buckling analysis of cross-ply laminated plates. Mechanics Research Communications. 2016;73:117-26.

[47] Najafizadeh M, Eslami M. Buckling analysis of circular plates of functionally graded materials under uniform radial compression. International Journal of Mechanical Sciences. 2002;44:2479-93.

[48] Hafizi ZM, Epaarachchi J, Lau KT. Wave Propagation Scattering due to Defects on Thin Composite Plates. Journal of Mechanical Engineering and Sciences. 2013;5:602-10.

[49] Siswanto WA, Nagentrau M, Mohd Tobi AL. Prediction of residual stress using explicit finite element method. Journal of Mechanical Engineering and Sciences. 2015;9:1556-70.

[50] Djamaluddin F, Abdullah S, Arrifin AK, Nopiah ZM. Modeling and Optimization of Aluminum Foam Cylindrical Double Tubes under Axial Impact. Journal of Mechanical Engineering and Sciences. 2015;8:1382-92.

[51] Roslan SAH, Hassan MZ, Rasid ZA, Zaki SA, Daud Y, Aziz S, et al. Mechanical properties of bamboo reinforced epoxy sandwich structure composites. International Journal of Automotive and Mechanical Engineering. 2015;12:2882-92.

[52] Saad AA, Bachok Z, Sun W. A study on the damage evolution of P91 steel under cyclic loading at high temperature. International Journal of Automotive and Mechanical Engineering. 2016;13:3564-73.

[53] Shimpi RP. Re ned plate theory and its variants. AIAA journal. 2002;40.

[54] Shimpi R, Patel H. A two variable refined plate theory for orthotropic plate analysis. International Journal of Solids and Structures. 2006;43:6783-99.

[55] Kim S-E, Thai H-T, Lee J. Buckling analysis of plates using the two variable refined plate theory. Thin-Walled Structures. 2009;47:455-62.

[56] Thai H-T, Kim S-E. Free vibration of laminated composite plates using two variable refined plate theory. International Journal of Mechanical Sciences. 2010;52:626-33.

[57] Kim S-E, Thai H-T, Lee J. A two variable refined plate theory for laminated composite plates. Composite Structures. 2009;89:197-205.

[58] Mechab I, Atmane HA, Tounsi A, Belhadj HA. A two variable refined plate theory for the bending analysis of functionally graded plates. Acta Mechanica Sinica. 2010;26:941-9.

[59] Gowda R, Pandalai K. Thermal buckling of orthotropic plates. Studies in Structural Mechanics. 1970:9-44.

[60] Thangaratnam KR, Ramachandran J. Thermal buckling of composite laminated plates. Computers \& Structures. 1989;32:1117-24. 